\title{
Fondo peruano y aportes europeos en la definición del pensamiento de Mariátegui
}

ANTONIO MELIS*

1. Las investigaciones de los últimos años han ido aclarando en términos generales la trayectoria ideológica de José Carlos Mariátegui. Una serie de aportes documentales nos han permitido comprobar la importancia de las experiencias anteriores al viaje europeo. En primer lugar, ha llamado la atención sobre sus contactos con las vanguardias literarias, que le permiten asimilar una actitud abierta hacia la experimentación artística, a la cual se conservará fiel durante toda su vida. En segundo lugar han destacado su adhesión al movimiento de reforma universitaria, episodio peruano de un proceso que tiene un carácter latinoamericano. A través de la participación en esta agitación renovadora, Mariátegui se enfrenta con la problemática planteada por los aparatos del consenso dentro de la sociedad burguesa. En tercer lugar, han puesto en relieve el contacto del-joyen intelectual, sobre todo en la breve pero intensa época del diario $L a$ Razon $n^{1}$, con el movimiento obrero peruano, durante la fase pionera de la lucha por la jornada de ocho horas. Es una experiencia decisiva para la colocación subjetiva de Mariátegui dentro del movimiento obrero revolucionario.

A pesar de los elementos aquí mencionados, es indudable que el período transcurrido en Europa representa un salto de calidad en la definición teórica de nuestro autor. Trataremos de resumir las razones fundamentales de este juicio, a partir de justamente de los terrenos de investigación que acabamos de citar arriba. Nuestra propuesta

* Jefe del Departamento de Español de la Universidad de Siena. Profesor Ho. norario de la UNMSM.

${ }^{1}$ Sobre esta etapa véase el libro de Juan Gargurevich, La Razón del joven Mariátegui. Crónica del primer diario de izquierda en el Perú, Lima, Editorial Horizonte, 1978. 
metodológica se funda en la consideración de la experiencia peruana anterior al viaje europeo como una base de potencialidades, en la que se va a injertar el encuentro traumático y exaltante con la Europa recién salida de la primera guerra mundial.

2. El panorama cultural del viejo continente, en el momento en que Mariátegui llega a Europa, es particularmente estimulante para el joven observador. Las consecuencias de la recién terminada guerra mundial se perciben claramente y profundamente en los medios intelectuales. Dentro de los mismos grupos de vanguardia, que habían enunciado sus primeros proclamas ya en los años anteriores al conflicto, la guerra representa un punto de referencia para su definición. El belicismo de los futuristas italianos, por ejemplo, que ya en su primer manifiesto habían declarado la guerra "sola higiene del mundo", se enfrenta violentamente con el rechazo radical de la locura guerrera por los dadaístas. Al mismo tiempo, dentro de las propias trincheras, se va gestando una literatura yinculada con la experiencia material de la guerra, en abierto contraste con toda exaltación retórica y patriotera.

La última fase de la guerra ha sido acompañada por el estallido de la Revolución de Octubre, con el establecimiento del poder soviético en Rusia. CuandolMariátegui vieja a Europa, empiezan ya a manifestarse los primerose ęisodiosidela fuevaecultura y política cultural de la Unión Soviética. En su afán de apoderarse de todas las novedades significativas, nuestro autor analiza tempestivamente estos aspectos.

Su producción crítica en todos los años siguientes refleja con gran evidencia el impacto producido por esta experiencia europea. El contacto con la vanguardia peruana en los años de bohemia (sobre todo con la figura genial de Abraham Valdelomar) ha ido preparando el terreno para acoger con sensibilidad artística y apertura ideológica las nuevas búsquedas al mismo tiempo, la confrontación directa de la literatura europea con la base histórico-social de la que surge, le permite separar con juicios acertados los productos auténticos de los que representan meras concesiones a la moda.

Asimismo, después del regreso a su patria, Mariátegui puede intervenir activamente en el desarrollo de la nueva literatura como 
elemento dinamizador. Sobre todo a partir de la fundación de Amauta (1926), dispone de un formidable instrumento para orientar a los jóvenes escritores peruanos. $\mathrm{Y}$ es impresionante constatar su capacidad de individualizar sin sectarismo los valores efectivos, prescindiendo de la postura ideológica expresada por cada autor.

La compleja fenomenología de la vanguardia europea le ha vuelto muy sagaz en el rechazo de toda identificación inmediatista entre afirmaciones ideológicas y logros estéticos. En Europa ha llegado a reconocer la superioridad de la narrativa de Joyce sobre cualquier forma de neopopulismo ${ }^{2}$. En Perú, en coherencia con estas proposiciones, él abre las páginas de su revista a los jóvenes que tratan de renovar el lenguaje literario, aun cuando éstos, como en el caso bien conocido de Martín Adán, se autoproclamen reaccionarios.

Interpretar esta actitud como mera demostración de tolerancia, significaría caer en una equivocación muy grave. Mariátegui, por supuesto, no se limita a la registración pasiva de las tendencias existentes, sino que reconoce en ellas las motivaciones profundas, que trascienden las intenciones explícitas.

Esta síntesis original de Perú y Europa o, en otras palabras, este itinerario Perú-Europa-Perú, permite a Mariátegui la realización de una experiencia única en sufépocal Es muy difícil identificar con

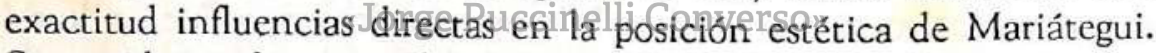
Son evidentes las coincidencias, a veces asombrosas, con las reflexiones sobre el arte y la literatura de Antonio Gramsci. Pero los datos materiales nos prueban que es imposible cualquier contacto directo, puesto que estas elaboraciones gramscianas se conocen solamente después de la segunda guerra mundial, cuando Mariátegui había desaparecido muchos años antes.

Entonces no puede tratarse de una filiación mecánica, sino más bien de una coincidencia, que tiene su raíz en una interpretación común del marxismo. En Mariátegui (como en Gramsci) la aceptación del marxismo como ciencia de la economía y la sociedad se une

${ }^{2}$ Véase el fundamental trabajo "Populismo literario y estabilización capitalista", Amauta, Lima, № 28, enero de 1930, pp. 6-9, ahora en: El artista y la época, Lima, Biblioteca Amauta, 1959, pp. 32-36. 
al rechazo de cualquier interpretación totalizante de la doctrina, como llave que pueda abrir todas las puertas. De allí surge la observación de Gramsci sobre la imposibilidad de interpretar la obra literaria a la luz de una relación mecánica con su época ${ }^{3}$. Dicho sea de paso, con estos planteamientos Gramsci se remontaba coherentemente al mismo Marx, con sus conocidas afirmaciones acerca del arte y la literatura griega ${ }^{4}$. Mariátegui, que coincidía perfectamente con estas apreciaciones, pudo a través de su revista practicar concretamente, aunque por un período de tiempo limitado, una polítca cultural inspirada en estos principios.

Se ha alegado muchas veces, para explicar estos y otros puntos de contacto entre los dos pensadores y dirigentes políticos, la existencia de una fuente común en la interpretación del marxismo proporcionada por Benedetto Croce. Por supuesto no se puede descartar la influencia de una personalidad dominante en la cultura italiana en aquel período. Pero es evidente la imposibilidad de reducir y banalizar el pensamiento tanto de Gramsci como de Mariátegui al idealismo neohegeliano y al liberalismo. Tah vez sea más rica en sugerencias, si queremos seguir una línea genealógica, la indicación de una fuente anterior al mismo Croce, la de su gran maestro en marxismo Antonio Labriola, bastante traicionado, por otra parte, por su ilustre alumno.

Se trata solamente deunachipỏtesis de trabajo, que habría que averiguar con un análisiscuidadospde los textos, Pero existe un punto de partida certero en el conocimiento que ambos autores tenían de la obra del fundador del marxismo italiano. En Gramsci esta relación con la obra del filósofo napolitano es evidente en todo su itinerario. En Mariátegui tenemos una serie de indicios que reflejan una utilización de Labriola en su aprendizaje marxista.

3. Si ahora pasamos a considerar la evolución del pensamiento de Mariátegui sobre la organización de la cultura, será bastante fácil encontrar una relación análoga entre premisas peruanas y desarrollo propiciado por la estancia en Europa. Ya se ha destacado la importancia de su participación en la agitación estudiantil en los años anteriores

${ }^{3}$ Antonio Gramsci, Letteratura e vita nazionale. Torino, Einaudi, 1954, p. 6.

${ }^{4}$ Karl Marx, Introduzione alla critica dell'economia politica. En: Per la critica dell'economia politica, Roma, Editori Riuniti, 1957, p. 197. 
a su salida del Perú. En Europa se encuentra frente a un despliegue de los aparatos culturales inmensamente más amplio y eficaz que en su país. Si el movimiento reformista universitario le había permitido un primer nivel de percepción de las formas ideológicas a través de las cuales se expresa el dominio, la experiencia de los países europeos le ofrece el ejemplo de una articulación más refinada y difundida en el tejido social de la ideología.

Es evidente que en Perú tampoco es totalmente ausente la búsqueda del consenso, pero es cierto que predomina el ejercicio de la fuerza. No hay que olvidarse que el mismo viaje de Mariátegui a Europa, por otra parte tan fecundo para su formación, es un episodio elocuente de la voluntad del poder de ahogar toda voz de oposición, utilizando también formas eufemistas como la de la misión de propaganda. El encuentro con la organización cultural del Viejo Continente sirve para afianzarlo en su intuición del papel fundamental de la batalla ideológica. Frente a la concentración de fuerzas no solamente materiales de las que disponen las clases dominantes, Mariátegui advierte la necesidad de una acumulación análoga para el propietario.

Desde su regreso al país llevará a cabo un proyecto de amplio alcance, para juntar todas las energías disponibles en la tarea de reno-

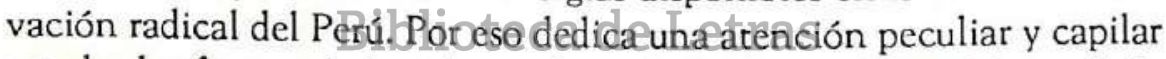
a todas las formas de laryida intelectualoSe-acupa del problema de la Biblioteca Nacional, considerando sus deficiencias de fondos bibliográficos como la expresión de un concepto angosto y aún colonial. Analiza hasta aspectos que pueden parecer marginales, como por ejmplo los premios literarios. ${ }^{5}$. En el fondo, se percibe un programa orgánico de intervención en el conjunto de las estructuras culturales.

Por otra parte, en la dirección de la revista Amauta, Mariátegui cumple un papel importante de orientación acerca del problema educacional en todos sus niveles. Al centro del interés y de la elaboración se mantiene la lucha por la reforma universitaria. También en este terreno nuestro autor no se limita al debate general, sino que interviene, directamente o a través de sus colaboradores, en los distintos

${ }^{5}$ Estos artículos se hallan reunidos en la última parte del tomo xIV de las obras de Mariátegui, Temas de educación, Lima, Biblioteca Amauta, 1970. 
momentos de la vida universitaria. La elección de un nuevo rector en la Universidad de San Marcos puede representar la ocasión para una toma de posición cortante de la revista. Pero al mismo tiempo se publican contribuciones relativas a la enseñanza de sendas disciplinas, proporcionanado un material de trabajo explícitamente vinculado con la vida diaria de la institución universitaria, en sus distintas faculta$\operatorname{des}^{6}$.

En Perú, antes del viaje a Europa, Mariátegui ha percibido las potencialidades revolucionarias del movimiento estudiantil. En Europa ha asistido a la degeneración de la rebeldía pequeño-burguesa, ya anunciada a nivel literario por el movimiento futurista, con su adhesión a la reacción fascista. Al mismo tiempo se ha dado cuenta de los errores cometidos por el movimiento obrero de la mayoría de los países europeos en la formulación de su táctica de alianzas. Aun rechazando en forma muy neta todo mito generacional ${ }^{7}$, reconoce la existencia de un problema vital de orientación de los sectores juveniles, que oscilan peligrosamente entre revolución y reacción.

El diseño lúcido y coherente de abrir con gran generosidad las páginas de Amauta a los jóvenes intelectuales, que ya hemos averiguado por lo que serefiere al terreno artístico y literario, corresponde a esta visión del proceso social. La novela y la vida, el singular relato escrito en la última fase de la breve estación de Mariátegui, refleja agudamente esta problemática. Es evidente la vinculación muy estrecha entre este orden de problemas y los temas más inmediatamente políticos de la relación entre proletariado y la pequeña burguesía. Podemos comprobarlo si pasamos a considerar el último punto de nuestro esquema de trabajo.

4. Los enemigos de Mariátegui, entre muchas otras formas de ataque contra su personalidad, han utilizado el argumento de su supuesta lejanía de la lucha de clases y en general de la vida política práctica. Nada de esto corresponde a la realidad, a pesar de las cono-

${ }^{6}$ Hemos tratado estos aspectos en un trabajo aparecido en la revista de Lima, Apuntes.

${ }^{7}$ Véase "El mito de la nueva generación". En: Defensa del marxismo, Lima, Biblioteca Amauta, 1974, vi ed., pp. 111-116. 
cidas limitaciones físicas que sufrió nuestro autor. Su encuentro con el proletariado se realiza, como decíamos arriba, durante la lucha por la jornada de ocho horas. Esta ocasión constituye para el joven dirigente político en formación un observatorio formidable para conocer las peculiaridades del movimento obrero peruano.

Como en otros países de América Latina, predominan en el proletariado peruano las ideas anarco-sindicalistas, que se mezclan con fuertes residuos de la tradición gremialista. Ambos filones coinciden en un aspecto fundamental, es decir el rechazo de la dimensión política, del enfrentamiento con el problema del Estado.

En Europa Mariátegui conoce un proletariado muy distinto, aunque con la presencia de sectores que reflejan problemas análogos a los de América Latina. Durante este período afina sus instrumentos teóricos, reflexionando sobre las recientes victorias y derrotas de la clase obrera. Por un lado el ejemplo entusiasmante de Rusia, por el otro la trágica involución de Italia. Las enseñanzas que saca de estos procesos presentan dos aspectos fundamentales, distintos aunque, por otra parte, complementarios.

La Revolución de Octubre, que el joven Antonio Gramsci en un artículo memorable había saludado como "Reyolución contra $E l \mathrm{Ca}$ pital", representa una enotme reafirmación del papel del sujeto en la lucha de clases. Contra ja tradición del marxismo empapado de positivismo de la Segunda Internacional, con su visión fatalista de los procesos sociales, el triunfo del poder soviético se presenta a Mariátegui como una comprobación de la iniciativa subjetiva en la ruptura revolucionaria. Al mismo tiempo el fracaso del socialismo italiano, desgarrado entre las opuestas impotencias del reformismo y el maximalismo, le proporciona un cuadro ejemplar y decisivo de los errores históricos del movimiento obrero.

La reivindicación del protagonismo subjetivo, de la "creación heroica" del socialismo peruano, es una constante en la acción de Mariátegui después de la vuelta a su patria. No se puede comprender en forma cabal su relación con el pensamiento de Georges Sorel así como otras influencias "irracionalistas" sin esta aclaración. La exigencia de un mito, como motor de la acción revolucionaria, le aparece 258 
imprescindible frente a las características del movimiento obrero peruano y al enredo entre problema de clases y problema étnico.

Al mismo tiempo, en la situación específica del Perú, con su clase obrera minoritaria y su proletariado ideológicamente atrasado, se vuelve urgente el desarrollo de una política de alianzas. El proceso de ida y vuelta entre Perú y Europa se manifiesta en este caso en una intuición creadora, que tiene un carácter objetivamente precursor de la política de los Frentes Populares. Pero no hay que olvidarse que esta línea surgió en la Internacional Comunista después de la derrota sufrida por el movimiento obrero con el arribo al poder del nazismo en esa Alemania que, durante largo tiempo, se había considerado como el país más cercano a una nueva revolución socialista. En la elaboración de Mariátegui, en cambio, se asomaba la posibilidad de una interpretación no defensiva de la política unitaria.

La historia del movimiento obrero peruano queda aún inexplorada en algunos de sus momentos cruciales. Podemos, por lo tanto, formular con mucha cautela la hipótesis conclusiva de esta propuesta. Observando con atención los números de Amauta aparecidos después de la muerte de su fundador, nos parece posible individualizar los síntomas de un hiato que se está produciendo. Por supuesto las premisas de esta fractura debianbes̀at en gestación yalanteriormente. Pero la

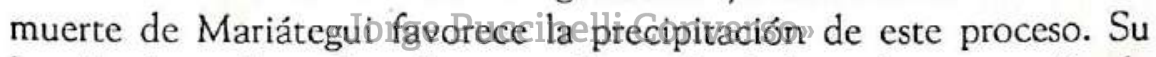
lección de estilo en la polémica política, fundada en la concepción de la verdad no como algo existente desde siempre y listo para el uso, sino como un resultado que hay que conseguir continuamente a través de la confrontación y del choque entre las distintas perspectivas, queda rápidamente abandonada. Pensamos que entre las tareas pendientes, además de la labor filológica imprescindible, se encuentre la de reanudar el cambio interrumpido del más grande marxista de América. 